\title{
Downregulation of decidual SP1 and P300 is associated with severe preeclampsia
}

\author{
Yachao Zhang1,2,3,*, Jieqiong Yang1,2,*, Shijian Lv1,2, Dong-Qin Zhao3, Zi-Jiang Chen',2, Wei-Ping Li1,2 and \\ Cong Zhang1,2,3
}

'Center for Reproductive Medicine, Ren Ji Hospital, School of Medicine, Shanghai Jiao Tong University, Shanghai, China 2Shanghai Key Laboratory for Assisted Reproduction and Reproductive Genetics, Shanghai, China

${ }^{3}$ Key Laboratory of Animal Resistance Biology of Shandong Province, College of Life Science, Shandong Normal University, Ji'nan, Shandong, China

Correspondence should be addressed to C Zhang or Z-J Chen or W-P Li: zhangxinyunlife@163.com or chenzijiang@hotmail.com or liweiping@renji.com *(Y Zhang and J Yang contributed equally to this work)

\begin{abstract}
Preeclampsia (PE) is a pregnancy-induced disorder characterized by hypertension and proteinuria after 20 weeks of gestation, affecting $5-7 \%$ of pregnancies worldwide. So far, the etiology of PE remains poorly understood. Abnormal decidualization is thought to contribute to the development of PE. SP1 belongs to the Sp/KLF superfamily and can recruit P300 to regulate the transcription of several genes. SP1 is also very important for decidualization as it enhances the expression of tissue factor. In this study, we investigated the expression of SP1 and P300 in deciduae and their relationship with PE. A total of 42 decidua samples were collected, of which 21 were from normal pregnant (NP) and 21 from severe PE. SP1 and P300 expression in deciduae and the levels of SP1 and P300 in cultured human endometrial stromal cells ( $\mathrm{hESCS}$ ) and primary hESCs during decidualization were determined. To further investigate the role of SP1 and P300 in human decidualization, RNA interference was used to silence SP1 and P300 in hESCs and primary hESCs. The following results were obtained. We found that the expressions of SP1 and P300 were reduced in decidual tissues with PE compared to those from NP. In the in vitro model of induction of decidualization, we found an increase in both SP1 and P300 levels. Silencing of $S P 1$ and $P 300$ resulted in abnormal decidualization and a significant reduction of decidualization markers such as insulin-like growth factor-binding protein 1 and prolactin. Furthermore, the expression of vascular endothelial growth factor was also decreased upon SP1 and $P 300$ silencing. Similar results were observed in primary hESCs. Our results suggest that SP1 and P300 play an important role during decidualization. Dysfunction of SP1 and P300 leads to impaired decidualization and might contribute to PE.
\end{abstract}

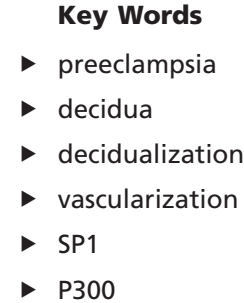

Journal of Molecular Endocrinology (2018) 60, 133-143

\section{Introduction}

Preeclampsia (PE) is a pregnancy-specific disorder defined by new onset of hypertension and proteinuria after 20 weeks of gestation. PE is unique to humans, affecting 2-7\% of pregnancies (Hauth et al. 2000, Sibai et al. 2005).
It is a serious disease and can lead to seizures (eclampsia), acute renal failure, acute liver injury, pulmonary edema and hemolysis. Children who are born to preeclamptic mothers usually have low birth weight and are at an 
increased risk of cardiovascular mortality in adulthood (Barker 1995). Although symptoms disappear after delivery, PE is one of the leading causes of maternal mortality and morbidity worldwide (Sibai et al. 1993, de Swiet 2000, Ghulmiyyah et al. 2012).

Knowledge of PE pathogenesis has increased in the past few decades. Previous studies have demonstrated that invasion of trophoblasts into spiral arteries is a very important process during the early stages of pregnancy. Abnormal placentation, particularly defective trophoblast invasion, is thought to cause PE in women (Winship et al. 2015). Furthermore, maternal spiral artery modification deficiency can lead to placental oxidative stress (Burton et al. 2009), endothelial dysfunction and inflammation (Maynard et al. 2003, Craici et al. 2008) and deregulation of immunological responses (Redman et al. 2009, Louwen et al. 2012) and contribute to the pathogenesis of PE. Furthermore, PE is also influenced by genetic and environmental factors and their interactions (Johansson et al. 2011).

Little attention has been focused on the decidua, into which the extravillous trophoblast (EVT) invades. Probably the 'soil,' rather than, or in addition to, the 'seed' is aberrant in women who develop PE (Brosens et al. 2002, Founds et al. 2009). Decidualization is essential for the maintenance of pregnancy and is regulated by the ovarian hormones (Wetendorf et al. 2012, Zhang et al. 2013). Decidualization occurs in the secretory phase, during which human endometrial stromal cells (ESCs) differentiate into larger and polygonal cells, transforming the endometrium into decidua, along with changes in their cellular function and gene expression. Decidual cells produce several characteristic growth factors and cytokines such as tissue factor (Lockwood et al. 1993), prolactin (PRL) (Daly et al. 1983) and insulin-like growth factor-binding protein 1 (IGFBP1) (Giudice et al. 1992). Thus, IGFBP1 and PRL have been useful as differentiation markers of decidual cells (Maslar et al. 1979, Dunn et al. 2003). Human uterine decidualization is a very important process, and it can affect all uterine compartments and cells, including spiral arteries, endometrial, epithelial, stromal compartments, junctional zone myocytes and local immune cells (Gellersen et al. 2007). Decidualization is thought to regulate trophoblast invasion and formation of placenta during early pregnancy. Furthermore, decidualization also plays an important role in immune tolerance of the semi-allogeneic fetus and isolates the mother and fetus from pathogens (Gellersen et al. 2007). Overall, placentation, embryo implantation and the establishment of pregnancy rely on appropriate decidualization of the endometrial stromal cells.

Specificity protein 1 (SP1) belongs to the Sp/Kruppellike factor (Sp/KLF) super-family. It is the first transcription factor to be purified and cloned from mammalian cells. It has highly conserved DNA-binding domains and three tandem zinc-finger motifs. SP1 is very important for decidualization as it regulates tissue factor expression by progestin (Krikun et al. 2000). Histone acetylation by histone acetyltransferase is one of the major mechanisms that regulates gene transcription. Histone acetyltransferase consists of three main families: GNAT Gcn5-related $\mathrm{N}$-acetyltransferase, P300 and cyclic AMP response element-binding protein (CREB), and MYST superfamily (Sterner et al. 2000). Previous studies have indicated that P300 interacts with specific transcription factors to regulate gene transcription and plays an important role in the process of cell proliferation and differentiation (Bannister et al. 1996, Ogryzko et al. 1996). SP1 can recruit P300 and interact with it to promote gene transcription (Li et al. 2013). It has also been reported that SP1 regulates angiogenesis via VEGF (Liu et al. 2016). In our previous work, we have demonstrated that expression of VEGF is reduced in the decidua of PE (Zhang et al. 2016). We therefore hypothesized that SP1 and P300 are associated with PE through decidualization. The aim of this study was to investigate the roles of SP1 and P300 in decidualization and their potential role in the pathogenesis of PE.

\section{Materials and methods}

\section{Study population}

All patients were recruited from the Qilu Hospital, Shandong University from Jan 2014 to Jan 2015. Only women with a singleton pregnancy were included. Exclusion criteria were women with collagen vascular disease, chronic hypertension, renal disease, diabetes mellitus, intra-partum infection, fetal abnormalities, chromosomal abnormalities and other diseases. The research was approved by the Ethics Committee of Qilu Hospital, and written informed consent was obtained from each patient. A total of 42 decidua samples were collected, of which 21 were from normal pregnant (NP) women who did not suffer from high blood pressure and proteinuria during pregnancy and delivered a healthy newborn after 37 weeks of pregnancy. The other 21 samples were from women with severe preeclampsia (SPE) women. SPE women are defined as women who previously had 
normal blood pressure and were subsequently diagnosed with a systolic blood pressure (SBP) of at least $160 \mathrm{mmHg}$ or a diastolic blood pressure (DBP) of at least $110 \mathrm{mmHg}$ and/or had proteinuria greater than either 2 on a dipstick or $5 \mathrm{~g}$ in 24 -h urine collection after 20 weeks of gestation.

\section{Decidual tissue collection}

All pregnancies were delivered by caesarean section. The decidual tissues were collected immediately after delivery from the gauze used to scrub the uterus. Collected tissues were washed with DEPC-treated saline three times to remove blood, snap-frozen in liquid nitrogen and stored at $-80^{\circ} \mathrm{C}$ before use.

\section{Real-time polymerase chain reaction (PCR) analysis}

TRIzol reagent (Invitrogen) was used to extract total RNA from tissues. Animal Total RNA Isolation Kit (Foregene, Chengdu, China) was utilized to extract total RNA from cells cultured in vitro as per the manufacturers' instructions, RNA integrity was assessed by electrophoresis. Intact tissue RNA samples $(1 \mu \mathrm{g})$ and cell RNA samples (500 ng) were converted to cDNA using the ReverTra Ace qPCR RT Kit (Toyobo, Osaka, Japan). Real-time PCR was performed using an Applied Biosystems Real-Time PCR system (Life Technologies) with the following conditions: initial denaturation for $10 \mathrm{~min}$ at $95^{\circ} \mathrm{C}$, followed by 40 cycles of $10 \mathrm{~s}$ at $95^{\circ} \mathrm{C}, 20 \mathrm{~s}$ at $59^{\circ} \mathrm{C}, 20 \mathrm{~s}$ at $72^{\circ} \mathrm{C}$ and a final extension for $5 \mathrm{~min}$ at $72^{\circ} \mathrm{C}$. Real-time PCR reactions were performed in triplicate with SYBR GREEN PCR Master Mix (Toyobo). Glyceraldehyde-3-phosphate dehydrogenase (GAPDH) was used as an internal control. Melting-curve analyses were carried out to verify the product identities and some of the amplicons were picked up randomly and were analyzed in $1.8 \%$ agarose gels to ensure the specificity of the PCR. The data were analyzed using the $\Delta \Delta$ Ct method (Pfaffl 2001, Bustin et al. 2009). The sequences of the primers for human SP1, P300, VEGF, PRL, IGFBP1 and GAPDH are given in Table 1.

\section{Human endometrial stromal cell (hESC) culture and treatment}

Immortalized hESC line was from the American Type Culture Collection (ATCCR CRL-4003TM). The cells were inoculated in $75 \mathrm{~cm}^{2}$ cell culture flasks and cultured in Phenol Red-free Dulbecco's modified Eagle's medium (DMEM)/F-12-containing glutamine (Life Technologies), $1 \%$ Insulin-Transferrin-Selenium (Invitrogen), $5 \times 10^{-2} \mathrm{~g} / \mathrm{L}$ antibiotics (Gibco) and $10 \%$ charcoalstripped foetal bovine serum (Biological Industries, Beit Haemek, Israel) at $37^{\circ} \mathrm{C}$ and $5 \% \mathrm{CO}_{2}$. To induce decidualization in vitro, $3 \times 10^{5}$ hESCs were incubated with DMEM/F12-containing 2\% charcoal-stripped FBS, $1 \mu \mathrm{mol} / \mathrm{L}$ medroxyprogesterone-17-acetate (MPA) (Sigma Chemical Co., St Louis, MO, USA) and $0.5 \mathrm{mmol} / \mathrm{L} \mathrm{N6}$, 20-O-dibutyryladenosine cAMP sodium salt (db-cAMP) (Sigma Chemical Co.) for 6 days with the medium being changed every two days. The cells were digested and counted using a TC20 automated cell counter (Bio-Rad Laboratories) on day 3 and day 6.

For RNAi, small interfering RNAs (siRNA) were purchased from Invitrogen. hESCs were plated in medium without antibiotics at approximately $4 \times 10^{5}$ cells per well in six-well plates. SiRNA $(2.5 \mu \mathrm{L} /$ per well $)$ and Lipofectamine RNAiMAX Reagent ( $9 \mu \mathrm{L} /$ well; Invitrogen) were diluted in Opti-MEM Medium (Gibco) and incubated at room temperature for $5 \mathrm{~min}$. The mixtures were then added to the cells in the six-well plates. After $24 \mathrm{~h}$, the medium was removed, and decidualization was induced in the cells for 4 days.

Table 1 Primer sequences.

\begin{tabular}{|c|c|}
\hline Gene & \\
\hline$S P 1$ & $\begin{array}{l}\text { Forward } \\
\text { Reverse }\end{array}$ \\
\hline P300 & $\begin{array}{l}\text { Forward } \\
\text { Reverse }\end{array}$ \\
\hline IGFBP1 & $\begin{array}{l}\text { Forward } \\
\text { Reverse }\end{array}$ \\
\hline$P R L$ & $\begin{array}{l}\text { Forward } \\
\text { Reverse }\end{array}$ \\
\hline VEGF & $\begin{array}{l}\text { Forward } \\
\text { Reverse }\end{array}$ \\
\hline GAPDH & $\begin{array}{l}\text { Forward } \\
\text { Reverse }\end{array}$ \\
\hline
\end{tabular}

\begin{tabular}{l}
\hline Sequences \\
\hline 5'-GGAGTTGGTGGCAATAATG-3' \\
5'-CCAGAGGAGGAAGAGATGA-3' \\
5'-ATCAGATGCCGACACAAC-3' \\
5'-TGAACTCCTACACCTCCAT-3' \\
5'-GGCACAGGAGACATCAGGAGAA-3' \\
5'-GGTAGACGCACCAGCAGAGT-3' \\
5'-CATATTGCGATCCTGGAATGAG-3' \\
5'-GATGAACCTGGCTGACTATCA-3' \\
5'-TCACCAAGGCCAGCACATAG-3' \\
5'-TTAACTCAAGCTGCCTCGCC-3' \\
5'-GGAGCGAGATCCCTCCAAAAT-3' \\
5'-GGCTGTTGTCATACTTCTCATGG-3'
\end{tabular}

\begin{tabular}{cc}
\hline Fragment size $(\mathrm{bp})$ \\
\hline 143 \\
136 \\
131 \\
158 \\
206 \\
197
\end{tabular}




\section{Primary endometrial stromal cell (ESC) isolation}

Primary ESCs were isolated from normal proliferative endometrial tissues obtained from cycling women by endometrial biopsy at the time of diagnostic hysteroscopy. The endometrial tissues were processed for stromal cell culture as described previously (Fernandez-Shaw et al. 1992). Briefly, the samples were suspended in PBS after washing twice in $0.9 \%$ normal saline. The tissues were then washed twice in DMEM/F12, chopped and digested with collagenase type I (c0130; Sigma Chemical Co.) for $70 \mathrm{~min}$ at $37^{\circ} \mathrm{C}$ and finally digested with deoxyribonuclease (DN25; Sigma Chemical Co.) for $20 \mathrm{~min}$ at $37^{\circ} \mathrm{C}$. The suspension was filtered through an $180 \mu \mathrm{m}$ griddle to remove mucus and undigested tissues and then through a $40 \mu \mathrm{m}$ griddle, which permits only stromal cells to pass. The primary ESCs were inoculated into $75 \mathrm{~cm}^{2}$ cell culture flasks first, and then used for decidualization induction and RNAi experiment under the same conditions described in the previous section for hESCs.

\section{Western blot analysis}

Total protein was isolated from decidual tissues and cultured hESCs using radio immunoprecipitation assay lysis buffer (Beyotime Biotechnology, Haimen, China) with protease inhibitors (Sigma Chemical Co.). Isolated proteins were quantified with an Enhanced BCA Protein Assay Kit (Thermo Fisher Scientific). The protein $(40 \mu \mathrm{g})$ was solubilized in a sample buffer consisting of $2 \%(\mathrm{w} / \mathrm{v})$ SDS, $62.5 \mathrm{mM}$ Tris- $\mathrm{HCl} \mathrm{pH}$ 6.8, 0.01\% (w/v) bromophenol blue, $25 \%(\mathrm{v} / \mathrm{v})$ glycerol, $5 \%(\mathrm{w} / \mathrm{v}) \quad \beta$-mercaptoethanol and boiled at $100^{\circ} \mathrm{C}$ for $5 \mathrm{~min}$. The boiled samples were electrophoresed using 8\% SDS-PAGE and transferred onto polyvinylidene difluoride membrane (GE Healthcare Life Sciences). The membrane was blocked with $5 \%$ non-fat milk for $90 \mathrm{~min}$ at room temperature. After blocking, the membrane was incubated with either the rabbit antihuman SP1 primary antibody (1:500; sc-14027, Santa Cruz Biotechnologies) or the rabbit anti-human P300 antibody (1:500; sc-585, Santa Cruz Biotechnologies) or the primary antibody against $\beta$-actin (1:5000; sc47778, Santa Cruz Biotechnologies) at $4^{\circ} \mathrm{C}$ overnight. The membrane was then washed with Tris-buffered saline containing 0.1\% Tween-20 three times and incubated with horseradish peroxidase-conjugated secondary antibody (1:5000) at room temperature for $1-2 \mathrm{~h}$. Detection was done using ECL chemiluminescence kit (Millipore). Bands were analyzed by Quantiscan software (Biosoft, Great Shelford, Cambridge, UK).

\section{Statistical analysis}

All data were analyzed using SPSS statistical 22 software (IBM). Differences between the two groups (SPE and NP) were analyzed by one-way analysis of variance and Student's $t$-test. The data are represented as means \pm S.E.M. and all experiments were repeated at least three times. A value of $P<0.05$ was regarded as statistically significant.

\section{Results}

\section{Clinical data of the participants}

The clinical information of the patients with SPE and the NP controls is shown in Table 2. There was no significant difference in the age between the NP and the SPE groups $(P>0.05)$. The DBP and SBP were significantly higher in the SPE group than those in the NP group. The gestational age and birth weight of newborns in the SPE group were lower than those in the NP group. The proteinuria of SPE patients was greater than 2 , while women in the NP group did not have proteinuria.

\section{Expression of SP1 and P300 in the decidual tissues of NP and SPE}

Real-time PCR data revealed that the mRNA levels of SP1 and P300 were significantly lower in the SPE group as compared to the NP group (Fig. 1A). Western blot result also showed that the expression of SP1 and P300 proteins in the decidual tissues of the SPE group was lower than that of the NP group (Fig. 1B).

\section{Expression of SP1 and P300 in decidualized hESCs}

To analyze the expression of SP1 and P300 during the process of decidualization, we induced decidualization

Table 2 Patient clinical characteristics of women with severe preeclampsia and normal pregnancy.

\begin{tabular}{|c|c|c|c|}
\hline & $\mathbf{N P}(n=21)$ & SPE $(n=21)$ & $P$ value \\
\hline Age (years) & $28.81 \pm 0.66$ & $29.81 \pm 1.13$ & 0.451 \\
\hline $\begin{array}{l}\text { Gestational age } \\
\text { (weeks) }\end{array}$ & $39.06 \pm 0.24$ & $36.65 \pm 0.61$ & $<0.01$ \\
\hline Birth weight (g) & $3607 \pm 124.80$ & $2599 \pm 185.10$ & $<0.01$ \\
\hline Proteinuria & - & $2+$ to $3+$ & N/A \\
\hline $\mathrm{SBP}(\mathrm{mmHg})$ & $120.5 \pm 3.39$ & $164.1 \pm 3.49$ & $<0.001$ \\
\hline $\mathrm{DBP}(\mathrm{mmHg})$ & $73.67 \pm 2.06$ & $104.4 \pm 2.48$ & $<0.001$ \\
\hline
\end{tabular}

All data are shown as means \pm S.E.M.

DBP, diastolic blood pressure; N/A, not applicable; NP, normal pregnant; SBP, systolic blood pressure; SPE, severe preeclampsia. 
A

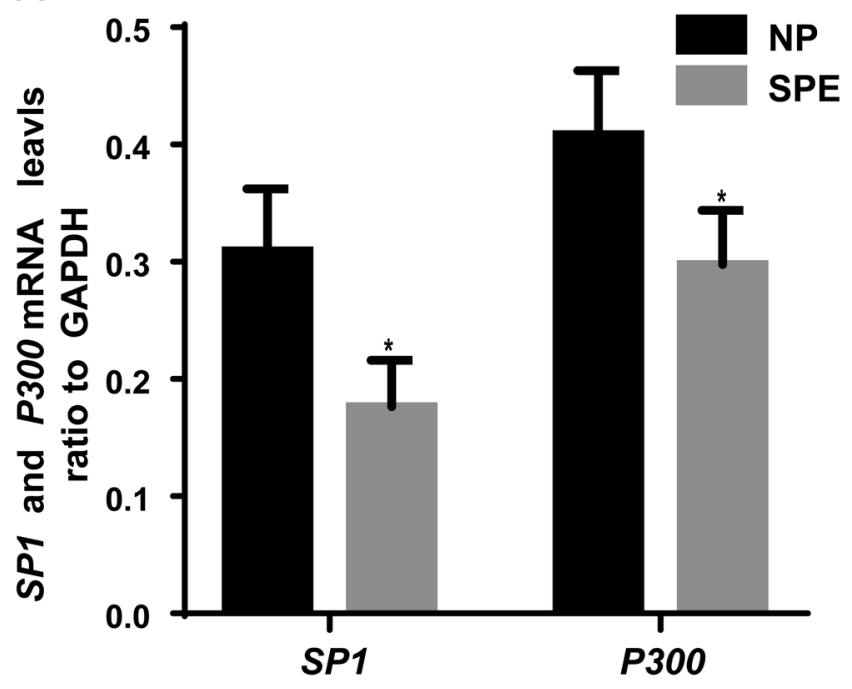

B
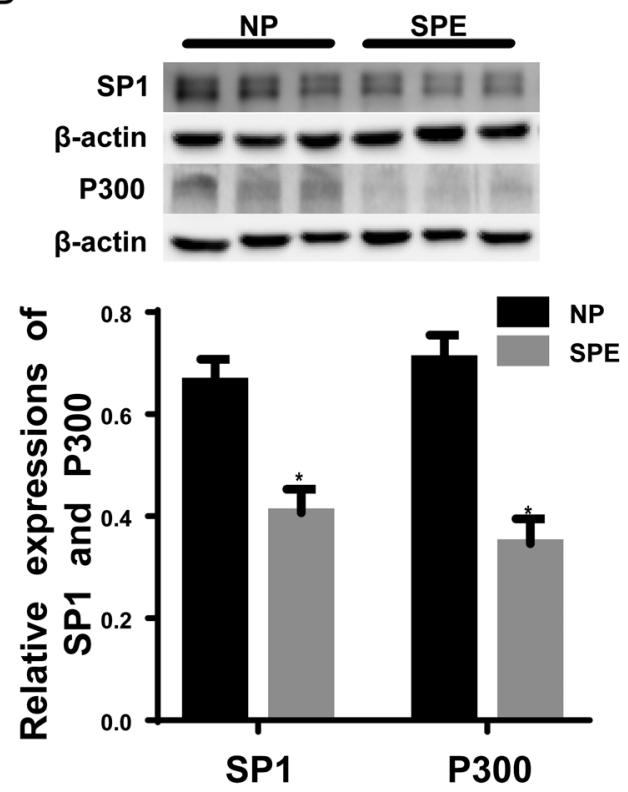

Figure 1

Levels of SP1 and P300 mRNA and protein in the decidual tissues. (A) SP1 and P300 mRNA levels in deciduae from NP $(n=21)$ and SPE $(n=21)$. (B) Expression of SP1 and P300 proteins relative to $\beta$-actin $(n=21$ for each group). The data are shown as mean \pm S.E.M. ${ }^{*} P<0.05$. NP, normal pregnant; SPE, severe preeclampsia.

using db-cAMP and MPA. Difference in cellular morphology could be observed between the two groups on day 3 . The untreated cells were spindle-shaped while the treated cells were enlarged and spherical (Supplementary Fig. 1E, see section on supplementary data given at the end of this article). Eventually, the morphology of decidualized cells became increasingly plump on day 6 (Supplementary Fig. 1F). Cell counting showed that cell numbers were
A

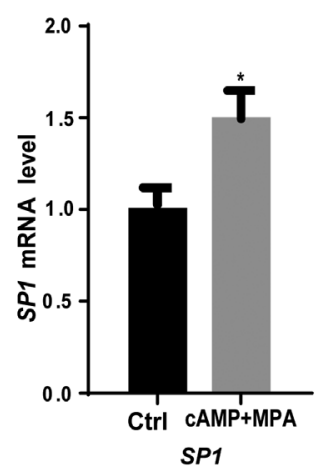

C
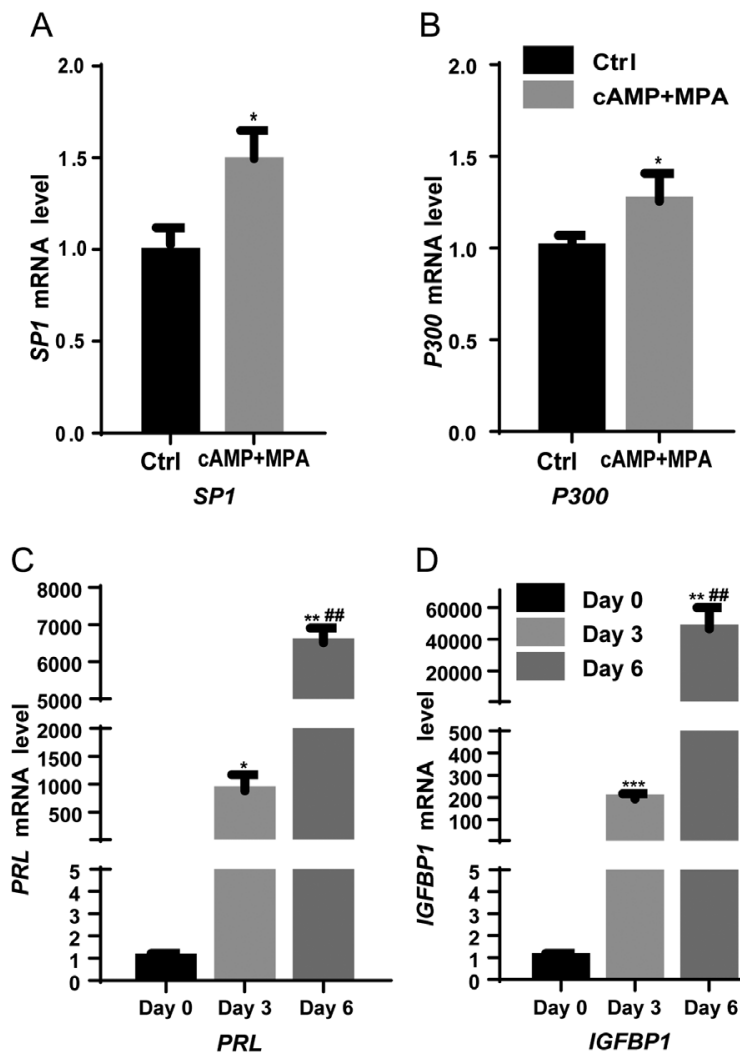

D

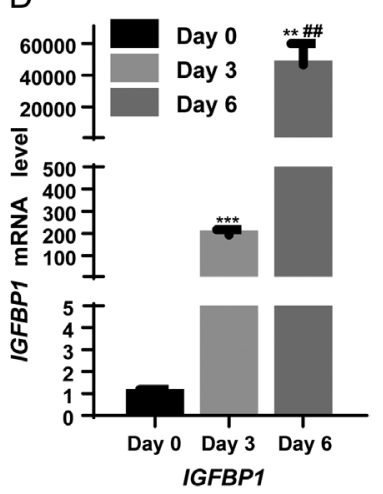

E

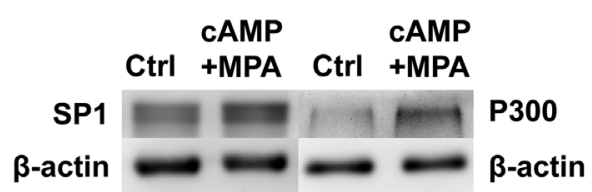

$\mathrm{F}$

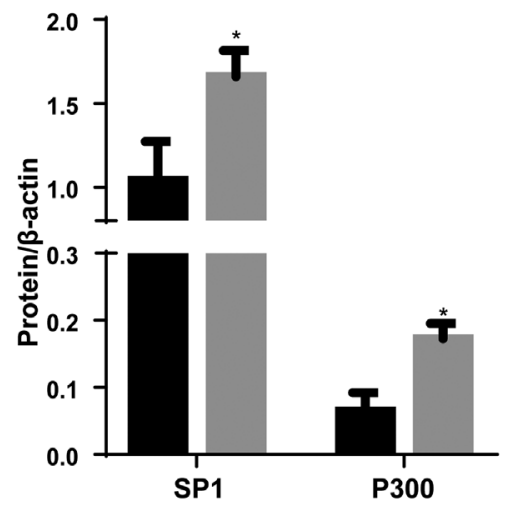

Figure 2

The expression of SP1, P300, IGFBP1 and PRL in hESCs after induced decidualization for 6 days. (A, B, C, and D) Expression of SP1, P300, IGFBP1 and PRL mRNA relative to GAPDH respectively. (E and F) Levels of SP1 and P300 proteins. All data are shown as mean \pm S.E.M. $* P<0.05$; $* * P<0.01 ; * * * P<0.001$ vs Ctrl or day 0 . $\# P<0.01$ vs day 3 . Ctrl, control hESCs; CAMP + MPA, treated hESCs. hESCs, human endometrial stromal cells. IGFBP1, insulin-like growth factor-binding protein 1; PRL, prolactin. 
significantly decreased in treated groups on day 3 and day 6 (Supplementary Fig. 1G).

When compared with untreated cells, the expression of SP1 and P300 on day 6 was upregulated at both mRNA and protein levels in the decidualized cells (Fig. 2A, B, $\mathrm{E}$ and $\mathrm{F}$ ). To test the reliability of the in vitro induction of decidualization, we evaluated the mRNAs of the endometrial decidualization biomarkers (IGFBP1 and PRL). We found that the levels of PRL and IGFBP1 mRNA were increased significantly with time (Fig. 2C and D).

\section{Silencing of SP1 and P300 affects decidualization}

To further investigate the role of SP1 and P300 in human decidualization, RNA interference was used to silence the expression of SP1 and P300 in hESCs. Real-time PCR results showed that the mRNA levels of the decidualization markers IGFBP1 and PRL were decreased significantly when SP1 or P300 was silenced (Fig. 3A and B). These findings suggested that silencing of $S P 1$ or $P 300$ blocked the decidualization reaction. To explore the mechanism of blocking in the absence of SP1 or P300, the expression of VEGFA mRNA was analyzed. As shown in Fig. 3C and $\mathrm{D}$, the transcription levels of this angiogenic gene were compromised upon SP1 or P300 siRNA treatment.

\section{Attenuation of SP1 and P300 led to impaired decidualization in primary ESCs}

To further confirm the results observed, we induced decidualization in primary endometrial stromal cells and analyzed them. When primary ESCs were treated with db-cAMP and MPA for 6 days, the morphology of decidualized cells was significantly altered when compared with their untreated counterparts (Supplementary Fig. 2A, $\mathrm{B}, \mathrm{C}, \mathrm{D}, \mathrm{E}$ and F). The expression of both $S P 1$ and $P 300$ was significantly upregulated on day 6 (Fig. $4 \mathrm{~A}$ and B), with simultaneous significant increase in the levels of $P R L$ and IGFBP1 mRNAs (Fig. 4C and D). Real-time PCR results showed that the mRNA levels of the decidualization markers IGFBP1 and PRL were decreased significantly when SP1 or P300 was silenced; the levels of VEGFA mRNA were also reduced (Fig. $5 \mathrm{~A}$ and $\mathrm{B}$ ).

\section{Discussion}

Owing to its high incidence and significant risk for both the mother and the fetus, PE has attracted increasing
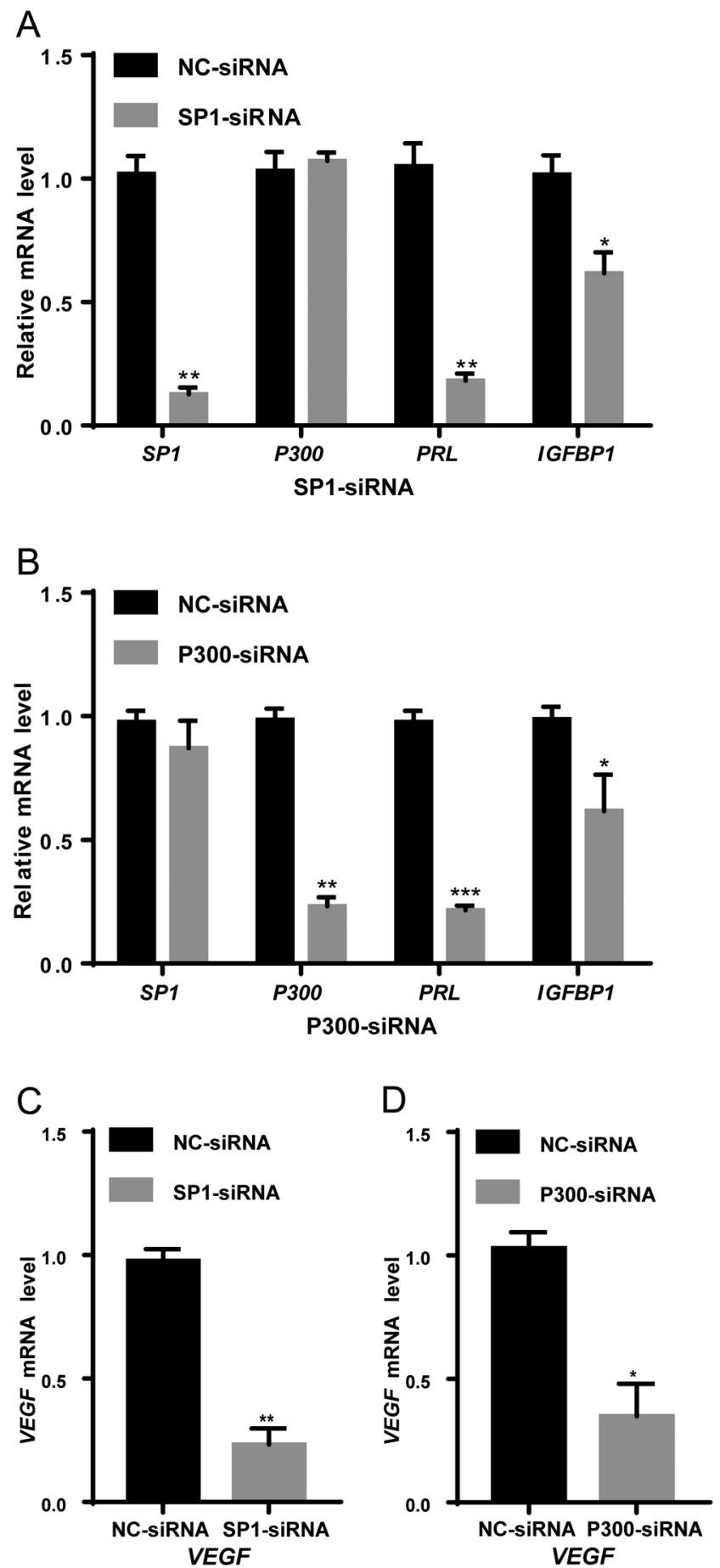

Figure 3

Effects of silencing of SP1 and P300 on decidualization. $24 \mathrm{~h}$ after transfection with SP1 or P300 siRNA, hESCs were treated with db-cAMP and MPA for 4 days. (A and C) mRNA expression of related genes after $S P 1$ was silenced. (B and $D$ ) mRNA expression of related genes after $P 300$ was silenced. All data are shown as mean \pm s.E.M. $* P<0.05 ; * * P<0.01$; $* * * P<0.001$. IGFBP1, insulin-like growth factor binding protein 1 ; $P R L$, prolactin; VEGF, vascular endothelial growth factor. 


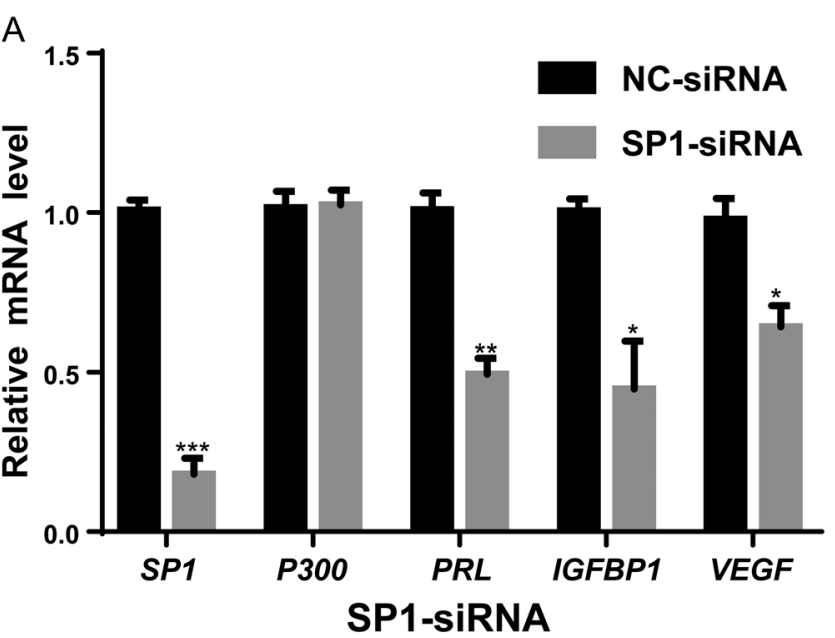

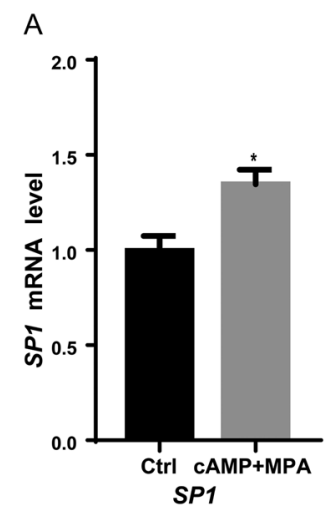
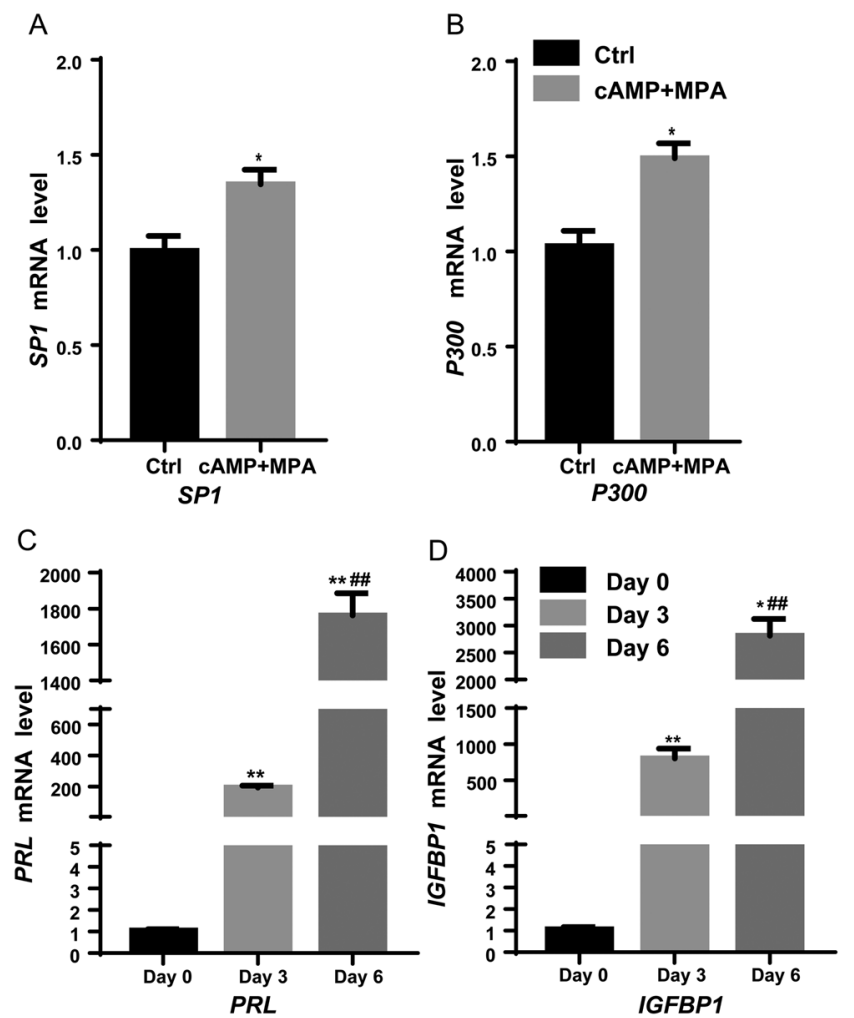

Figure 4

mRNA expression of SP1, P300, IGFBP1 and PRL in primary ESCs after induced decidualization. (A and B) mRNA levels of $S P 1$ and $P 300$ after induced decidualization for 6 days. (C and D) mRNA levels of IGFBP1 and $P R L$ after induced decidualization at 0,3 and 6 days. All data are shown as mean \pm s.E.M. ${ }^{*} P<0.05 ; * * P<0.01$ vs $C$ trl or day $0 . \# P<0.01$ vs day 3 . Ctrl, control primary ESCs; CAMP + MPA, treated primary ESCs. IGFBP1, insulin-like growth factor-binding protein 1; PRL, prolactin.

attention. Treatment of PE must ensure the safety of mothers; therefore, preterm delivery is the only way to ease PE symptoms. However, although preterm delivery is appropriate for mothers who suffer from SPE, it is not ideal for a premature fetus since preterm birth might cause cardiopulmonary dysplasia and perinatal mortality, as well as lower birth weight.

In this study, we investigated the roles of SP1 and P300 in decidualization. Our data showed that expression of SP1 and P300 both at mRNA and protein levels was significantly decreased in the deciduae of women who suffered from PE as compared to those from women with normal pregnancy. Using hESCs and primary ESCs, we found that the expression of SP1 and P300 was significantly increased at both mRNA and protein levels when compared with the control group after induction of decidualization. Furthermore, silencing of SP1 and P30O by siRNA reduced the expression of IGFBP1, PRL and VEGF both in cell lines as well as primary ESCs. These findings demonstrated that SP1 and P300 are critical

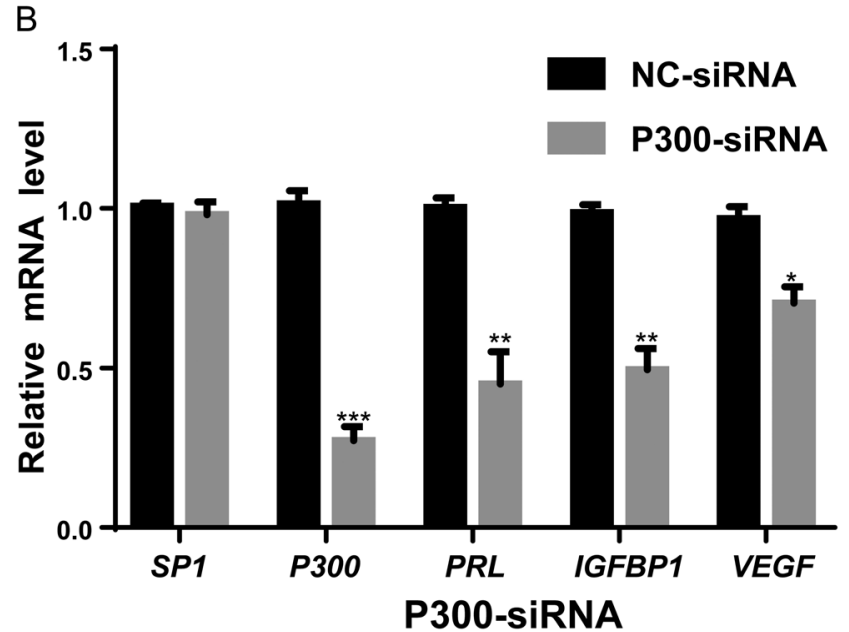

Figure 5

Effects of SP1 and P300 silencing on primary ESCs decidualization. (A) mRNA expression of related genes after SP1 was silenced. (B) mRNA expression of related genes after $P 300$ was silenced. All data are shown as mean \pm S.E.M. ${ }^{*} P<0.05 ; * * P<0.01 ; * * * P<0.001$. IGFBP1, insulin-like growth factor-binding protein 1; PRL, prolactin; VEGF, vascular endothelial growth factor.

for decidualization, and their dysfunction in deciduae obtained at caesarean section is associated with PE.

The Sp/KLF super-family has two subfamilies: Sp subfamily and KLF subfamily. SP1 is a member of the Sp subfamily and is ubiquitously expressed, and it transactivates the promoters of thousands of genes such as tissue factor (Krikun et al. 2000) and prolactin receptor (Hu et al. 1998). In addition, SP1 is activated in response to oxidative stress induced by hypoxia and induces the expression of several factors including VEGFA, COX2 and carbonic anhydrase 9. SP1 is also involved in the inflammatory response and other biological processes such as angiogenesis, cell growth and differentiation (Opitz \& Rustgi 2000, Liu et al. 2016). These processes play 
important roles in embryo differentiation, development and endometrial decidualization.

Several transcriptomic studies of preeclamptic placentas have identified a consensus list of regulated genes (Suzuki et al. 2004, Nishizawa et al. 2007, 2011, Winn et al. 2009, Tsai et al. 2011a,b, Meng et al. 2012), and their promoters are enriched in putative binding sites for SP1 (Vaiman et al. 2013). Sp1 interacts directly or indirectly with transcription-associated proteins, transcriptional regulators and chromatin remodeling factors (P300) to activate or repress gene expression (Suzuki et al. 2000). However, in our research, silencing of SP1 did not affect the expression of P300. Conversely, silencing of P300 did not affect SP1 expression, either.

The transcriptional coactivators P300 and CREB are histone acetyltransferases. They have similar sequences and functions and by themselves do not interact with DNA. P300 and CREB need to link certain transcription factors to regulate transcription. P300 was identified as a cellular interaction partner of adenovirus E1A oncoprotein and is inactivated upon binding to E1A (Mink et al. 1997). Lack of $P 300$ in mice leads to embryonic lethality (Yao et al. 1998). Furthermore, defects in P300 may cause Rubinstein-Taybi syndrome, a disorder characterized by mental retardation. A correlation has also been observed between PE and mothers of patients with P300 mutations (Tsai et al. 2011a,b). In our study, SP1 and P300 were both detected in the deciduae of NP and SPE, but the expression of SP1 and P300 was decreased in SPE when compared with NP. This observation suggests that abnormal expression of SP1 and P300 in deciduae could be related with PE.

In vitro induction of decidualization in our experiments resulted in the upregulation of SP1 and P300 at both mRNA and protein levels. In addition, silencing of SP1 and P300 caused downregulation of the decidualization markers IGFBP1 and PRL. Uterine decidualization is crucial during pregnancy for providing nutrition to the fetus before formation of the placenta (King 2000), regulation of trophoblast invasion and provision of immune protection. Thus, abnormal expression of important factors may cause impaired decidualization, thereby inducing PE. Our data showed that both SP1 and P300 are critical for decidualization. Reduced expression of SP1 and P300 jeopardizes decidualization and might increase the risk of PE.

Decidual angiogenesis is an important process for normal pregnancy development in the early postimplantation period. Human decidual cells express tissue factor during gestation, which is important in maintaining pregnancy. It has been reported that
SP1 regulates tissue factor expression via progestin (Krikun et al. 2000). Mice expressing lower amounts of tissue factor are susceptible to postpartum hemorrhage and death (Carmeliet et al. 1996). Furthermore, tissue factor is also related to angiogenesis (Hobbs et al. 2007). Furthermore, three Sp1 transcription factorbinding sites have been reported in the VEGF promoter region (Liu et al. 2016). It also has been reported that inhibition of the hypoxia-inducible factor $1 \alpha$ (HIF-1 $\alpha$ ) by disrupting its association with P300 inhibits angiogenesis (Goey et al. 2016). Additionally, we have found that HIF$1 \alpha$ expression was upregulated in decidualized cells on day 6 (data not shown). Thus, VEGF might be regulated by multiple signaling pathways during the process of decidualization. We speculate that SP1 recruits P300 to acetylated histones and promotes VEGF expression. VEGF has been reported to regulate the migration of trophoblasts, and inhibition of VEGF might impair uteroplacental blood flow. Disturbances in the angiogenesis signal pathways are related to PE, and altered expression of VEGF has been implicated in the pathophysiology of PE (Sandrim et al. 2008). In our previous studies, we have demonstrated that expression of VEGF decreased at both mRNA and protein levels in the deciduae of PE when compared with NP (Zhang et al. 2016). In the present study, our data show that silencing of SP1 or P300 leads to downregulation of VEGF during decidualization. We inferred that SP1 and P300 affect decidualization via VEGF. In addition, our previous study has also illustrated that COX2 regulates decidualization and PE via the VEGF pathway (Zhang et al. 2016). Further studies are needed to explore the relationships between SP1, P300, COX2, VEGF and acetylation of the VEGF promoter region.

To summarize the findings of this study suggest that SP1 and P300 are very important for decidualization of human endometrium, which is essential for pregnancy, including embryo development, trophoblast invasion and placentation. Abnormal expression of SP1 and P300 in decidual tissues may be associated with PE. This is consistent with the studies of others who also consider that defective decidualization might contribute to the genesis of PE (Conrad et al. 2017, Cottrell et al. 2017, Garrido-Gomez et al. 2017). A caveat is that, in the current study, we employed decidua obtained at delivery; as such, whether decidual dysregulation of SP1 and P300 is also associated with the genesis of PE transpiring in early pregnancy is unknown. PE is a multisystem disorder during pregnancy. Currently, preterm delivery is the only way to alleviate PE symptoms. Our study of SP1 and P300 in human decidualization provides new insights about the 
pathogenesis of PE and might bring about new paradigms in the mechanism and management of PE.

\section{Supplementary data}

This is linked to the online version of the paper at https://doi.org/10.1530/ JME-17-0180.

\section{Declaration of interest}

The authors declare that there is no conflict of interest that could be perceived as prejudicing the impartiality of the research reported.

\section{Funding}

This study was supported by the National Natural Science Foundation of China (NSFC: funding number: 31172040, 31471399, 31671199), National Key R\&D Program of China (2017YFC1001403) and Shanghai Municipal Education Commission--- Gaofeng Clinical Medicine Grant Support (20152515) to C Z, by the Major Program of National Natural Science Foundation of China (funding number: 81490743) to Z-J C, by NSFC (funding number: 81370692) to W-P L and by NSFC (funding number: 31501861) to D-Q Z as well as by the Shanghai Commission of Science and Technology (funding number: 17DZ2271100).

\section{Author contribution statement}

Y-C Z and J-Q Y designed and performed the experiments, supervised the experimental procedures, analyzed the data, coordinated the project and wrote the manuscript; S-J L and D-Q Z provided technical assistance. Z-J C, W-P $L$ and $C Z$ are the guarantors of this study.

\section{Acknowledgements}

The immortalized hESCs was a kind gift from Dr Haibin Wang (Institute of Zoology, Chinese Academy of Sciences, Beijing, China). The authors would like to thank all the patients and their relatives for their participation and help during this study.

\section{References}

Bannister AJ \& Kouzarides T 1996 The CBP co-activator is a histone acetyltransferase. Nature 384 641-643. (https://doi. org/10.1038/384641a0)

Barker DJ 1995 Fetal origins of coronary heart disease. BMJ $\mathbf{3 1 1}$ 171-174. (https://doi.org/10.1136/bmj.311.6998.171)

Brosens JJ, Pijnenborg R \& Brosens IA 2002 The myometrial junctional zone spiral arteries in normal and abnormal pregnancies: a review of the literature. American Journal of Obstetrics and Gynecology 187 1416-1423. (https://doi.org/10.1067/mob.2002.127305)

Burton GJ, Yung HW, Cindrova-Davies T \& Charnock-Jones DS 2009 Placental endoplasmic reticulum stress and oxidative stress in the pathophysiology of unexplained intrauterine growth restriction and early onset preeclampsia. Placenta 30 (Supplement A) S43-S48. (https://doi.org/10.1016/j.placenta.2008.11.003)

Bustin SA, Benes V, Garson JA, Hellemans J, Huggett J, Kubista M, Mueller R, Nolan T, Pfaffl MW, Shipley GL, et al. 2009 The MIQE guidelines: minimum information for publication of quantitative real-time PCR experiments. Clinical Chemistry 55 611-622. (https:// doi.org/10.1373/clinchem.2008.112797)

Carmeliet P, Mackman N, Moons L, Luther T, Gressens P, Van Vlaenderen I, Demunck H, Kasper M, Breier G, Evrard P, et al. 1996 Role of tissue factor in embryonic blood vessel development. Nature 383 73-75. (https://doi.org/10.1038/383073a0)

Conrad KP, Rabaglino MB \& Post UE 2017 Emerging role for dysregulated decidualization in the genesis of preeclampsia. Placenta 60 119-129. (https://doi.org/10.1016/j.placenta.2017.06.005)

Cottrell HN, Wu J, Rimawi BH, Duran JM, Spencer JB, Sidell N \& Rajakumar A 2017 Human endometrial stromal cell plasticity: reversible sFlt1 expression negatively coincides with decidualization. Hypertension in Pregnancy 36 204-211. (https://doi.org/10.1080/10641 955.2017.1299172)

Craici I, Wagner S \& Garovic VD 2008 Preeclampsia and future cardiovascular risk: formal risk factor or failed stress test? Therapeutic Advances in Cardiovascular Disease 2 249-259. (https://doi. org/10.1177/1753944708094227)

Daly DC, Maslar IA \& Riddick DH 1983 Prolactin production during in vitro decidualization of proliferative endometrium. American Journal of Obstetrics and Gynecology 145 672-678. (https://doi. org/10.1016/0002-9378(83)90572-0)

de Swiet M 2000 Maternal mortality: confidential enquiries into maternal deaths in the United Kingdom. American Journal of Obstetrics and Gynecology 182 760-766. (https://doi.org/10.1016/ S0002-9378(00)70324-3)

Dunn CL, Kelly RW \& Critchley HO 2003 Decidualization of the human endometrial stromal cell: an enigmatic transformation. Reproductive Biomedicine Online 7 151-161. (https://doi.org/10.1016/S14726483(10)61745-2)

Fernandez-Shaw S, Shorter SC, Naish CE, Barlow DH \& Starkey PM 1992 Isolation and purification of human endometrial stromal and glandular cells using immunomagnetic microspheres. Human Reproduction 7 156-161. (https://doi.org/10.1093/oxfordjournals. humrep.a137609)

Founds SA, Conley YP, Lyons-Weiler JF, Jeyabalan A, Hogge WA \& Conrad KP 2009 Altered global gene expression in first trimester placentas of women destined to develop preeclampsia. Placenta 30 15-24. (https://doi.org/10.1016/j.placenta.2008.09.015)

Garrido-Gomez T, Dominguez F, Quinonero A, Diaz-Gimeno P, Kapidzic M, Gormley M, Ona K, Padilla-Iserte P, McMaster M, Genbacev O, et al. 2017 Defective decidualization during and after severe preeclampsia reveals a possible maternal contribution to the etiology. PNAS 114 E8468-E8477. (https://doi.org/10.1073/ pnas.1706546114)

Gellersen B, Brosens IA \& Brosens JJ 2007 Decidualization of the human endometrium: mechanisms, functions, and clinical perspectives. Seminars in Reproductive Medicine 25 445-453. (https://doi. org/10.1055/s-2007-991042)

Ghulmiyyah L \& Sibai B 2012 Maternal mortality from preeclampsia/ eclampsia. Seminars in Perinatology 36 56-59. (https://doi. org/10.1053/j.semperi.2011.09.011)

Giudice LC, Dsupin BA \& Irwin JC 1992 Steroid and peptide regulation of insulin-like growth factor-binding proteins secreted by human endometrial stromal cells is dependent on stromal differentiation. Journal of Clinical Endocrinology and Metabolism 75 1235-1241. (https://doi.org/10.1210/jcem.75.5.1385468)

Goey AK, Chau CH, Sissung TM, Cook KM, Venzon DJ, Castro A, Ransom TR, Henrich CJ, McKee TC, McMahon JB, et al. 2016 Screening and biological effects of marine pyrroloiminoquinone alkaloids: potential inhibitors of the HIF-1alpha/p300 interaction. Journal of Natural Products 79 1267-1275. (https://doi.org/10.1021/ acs.jnatprod.5b00846)

Hauth JC, Ewell MG, Levine RJ, Esterlitz JR, Sibai B, Curet LB, Catalano PM \& Morris CD 2000 Pregnancy outcomes in healthy nulliparas who developed hypertension. Calcium for Preeclampsia 
Prevention Study Group. Obstetrics and Gynecology 95 24-28. (https:// doi.org/10.1016/S0029-7844(99)00462-7)

Hobbs JE, Zakarija A, Cundiff DL, Doll JA, Hymen E, Cornwell M, Crawford SE, Liu N, Signaevsky M \& Soff GA 2007 Alternatively spliced human tissue factor promotes tumor growth and angiogenesis in a pancreatic cancer tumor model. Thrombosis Research 120 (Supplement 2) S13-S21. (https://doi.org/10.1016/ S0049-3848(07)70126-3)

Hu ZZ, Zhuang L, Meng J \& Dufau ML 1998 Transcriptional regulation of the generic promoter III of the rat prolactin receptor gene by C/ EBPbeta and Sp1. Journal of Biological Chemistry 273 26225-26235. (https://doi.org/10.1074/jbc.273.40.26225)

Johansson A, Curran JE, Johnson MP, Freed KA, Fenstad MH, Bjorge L, Eide IP, Carless MA, Rainwater DL, Goring HH, et al. 2011 Identification of ACOX2 as a shared genetic risk factor for preeclampsia and cardiovascular disease. European Journal of Human Genetics 19 796-800. (https://doi.org/10.1038/ejhg.2011.19)

King A 2000 Uterine leukocytes and decidualization. Human Reproduction Update 6 28-36. (https://doi.org/10.1093/humupd/6.1.28)

Krikun G, Schatz F, Mackman N, Guller S, Demopoulos R \& Lockwood CJ 2000 Regulation of tissue factor gene expression in human endometrium by transcription factors Sp1 and Sp3. Molecular Endocrinology 14 393-400. (https://doi.org/10.1210/mend.14.3.0430)

Li J, Wang W, Liu C, Wang W, Li W, Shu Q, Chen ZJ \& Sun K 2013 Critical role of histone acetylation by p300 in human placental 11beta-HSD2 expression. Journal of Clinical Endocrinology and Metabolism 98 E1189-E1197. (https://doi.org/10.1210/jc.2012-4291)

Liu N, Ding D, Hao W, Yang F, Wu X, Wang M, Xu X, Ju Z, Liu JP, Song $\mathrm{Z}$, et al. $2016 \mathrm{hTERT}$ promotes tumor angiogenesis by activating VEGF via interactions with the Sp1 transcription factor. Nucleic Acids Research 44 8693-8703. (https://doi.org/10.1093/nar/ gkw549)

Lockwood CJ, Nemerson Y, Guller S, Krikun G, Alvarez M, Hausknecht V, Gurpide E \& Schatz F 1993 Progestational regulation of human endometrial stromal cell tissue factor expression during decidualization. Journal of Clinical Endocrinology and Metabolism 76 231-236. (https://doi.org/10.1210/jcem.76.1.8421090)

Louwen F, Muschol-Steinmetz C, Reinhard J, Reitter A \& Yuan J 2012 A lesson for cancer research: placental microarray gene analysis in preeclampsia. Oncotarget 3 759-773. (https://doi.org/10.18632/ oncotarget.595)

Maslar IA \& Riddick DH 1979 Prolactin production by human endometrium during the normal menstrual cycle. American Journal of Obstetrics and Gynecology 135 751-754. (https://doi. org/10.1016/0002-9378(79)90386-7)

Maynard SE, Min JY, Merchan J, Lim KH, Li JY, Mondal S, Libermann TA, Morgan LP, Sellke FW, Stillman IE, et al. 2003 Excess placental soluble fms-like tyrosine kinase 1 (sFlt1) may contribute to endothelial dysfimction, hypertension, and proteinuria in preeclampsia. Journal of Clinical Investigation 111 649-658. (https:// doi.org/10.1172/JCI17189)

Meng T, Chen H, Sun M, Wang H, Zhao G \& Wang X 2012 Identification of differential gene expression profiles in placentas from preeclamptic pregnancies versus normal pregnancies by DNA microarrays. OMICS: Journal of Integrative Biology 16 301-311. (https://doi.org/10.1089/omi.2011.0066)

Mink S, Haenig B \& Klempnauer KH 1997 Interaction and functional collaboration of p300 and C/EBPbeta. Molecular and Cellular Biology 17 6609-6617. (https://doi.org/10.1128/MCB.17.11.6609)

Nishizawa H, Pryor-Koishi K, Kato T, Kowa H, Kurahashi H \& Udagawa Y 2007 Microarray analysis of differentially expressed fetal genes in placental tissue derived from early and late onset severe pre-eclampsia. Placenta 28 487-497. (https://doi.org/10.1016/j. placenta.2006.05.010)

Nishizawa H, Ota S, Suzuki M, Kato T, Sekiya T, Kurahashi H \& Udagawa Y 2011 Comparative gene expression profiling of placentas from patients with severe pre-eclampsia and unexplained fetal growth restriction. Reproductive Biology and Endocrinology 9107. (https://doi.org/10.1186/1477-7827-9-107)

Ogryzko VV, Schiltz RL, Russanova V, Howard BH \& Nakatani Y 1996 The transcriptional coactivators $\mathrm{p} 300$ and CBP are histone acetyltransferases. Cell 87 953-959. (https://doi.org/10.1016/S00928674(00)82001-2)

Opitz OG \& Rustgi AK 2000 Interaction between Sp1 and cell cycle regulatory proteins is important in transactivation of a differentiation-related gene. Cancer Research 60 2825-2830.

Pfaffl MW 2001 A new mathematical model for relative quantification in real-time RT-PCR. Nucleic Acids Research 29 e45. (https://doi. org/10.1093/nar/29.9.e45)

Redman CW \& Sargent IL 2009 Placental stress and pre-eclampsia: a revised view. Placenta 30 (Supplement A) S38-S42. (https://doi. org/10.1016/j.placenta.2008.11.021)

Sandrim VC, Palei AC, Cavalli RC, Araujo FM, Ramos ES, Duarte G \& Tanus-Santos JE 2008 Vascular endothelial growth factor genotypes and haplotypes are associated with pre-eclampsia but not with gestational hypertension. Molecular Human Reproduction 15 115-120. (https://doi.org/10.1093/molehr/gan076)

Sibai BM, Ramadan MK, Usta I, Salama M, Mercer BM \& Friedman SA 1993 Maternal morbidity and mortality in 442 pregnancies with hemolysis, elevated liver enzymes, and low platelets (HELLP syndrome). American Journal of Obstetrics and Gynecology 169 1000-1006. (https://doi.org/10.1016/0002-9378(93)90043-I)

Sibai B, Dekker G \& Kupferminc M 2005 Pre-eclampsia. Lancet 365 785-799. (https://doi.org/10.1016/S0140-6736(05)71003-5)

Sterner DE \& Berger SL 2000 Acetylation of histones and transcriptionrelated factors. Microbiology and Molecular Biology Reviews 64 435-459. (https://doi.org/10.1128/MMBR.64.2.435-459.2000)

Suzuki T, Kimura A, Nagai R \& Horikoshi M 2000 Regulation of interaction of the acetyltransferase region of p300 and the DNAbinding domain of Sp1 on and through DNA binding. Genes to Cells 5 29-41. (https://doi.org/10.1046/j.1365-2443.2000.00302.x)

Suzuki Y, Yamashita R, Sugano S \& Nakai K 2004 DBTSS, DataBase of Transcriptional Start Sites: progress report 2004. Nucleic Acids Research 32 D78-D81. (https://doi.org/10.1093/nar/gkh076)

Tsai AC, Dossett CJ, Walton CS, Cramer AE, Eng PA, Nowakowska BA, Pursley AN, Stankiewicz P, Wiszniewska J \& Cheung SW 2011a Exon deletions of the EP300 and CREBBP genes in two children with Rubinstein-Taybi syndrome detected by aCGH. European Journal of Human Genetics 19 43-49. (https://doi.org/10.1038/ejhg.2010.121)

Tsai S, Hardison NE, James AH, Motsinger-Reif AA, Bischoff SR, Thames BH \& Piedrahita JA 2011b Transcriptional profiling of human placentas from pregnancies complicated by preeclampsia reveals disregulation of sialic acid acetylesterase and immune signalling pathways. Placenta 32 175-182. (https://doi.org/10.1016/j. placenta.2010.11.014)

Vaiman D, Calicchio R \& Miralles F 2013 Landscape of transcriptional deregulations in the preeclamptic placenta. PLOS ONE 8 e65498. (https://doi.org/10.1371/journal.pone.0065498)

Wetendorf M \& DeMayo FJ 2012 The progesterone receptor regulates implantation, decidualization, and glandular development via a complex paracrine signaling network. Molecular and Cellular Endocrinology 357 108-118. (https://doi.org/10.1016/j. mce.2011.10.028)

Winn VD, Gormley M, Paquet AC, Kjaer-Sorensen K, Kramer A, Rumer KK, Haimov-Kochman R, Yeh RF, Overgaard MT, Varki A, et al. 2009 Severe preeclampsia-related changes in gene expression at the maternal-fetal interface include sialic acid-binding immunoglobulin-like lectin-6 and pappalysin-2. Endocrinology 150 452-462. (https://doi.org/10.1210/en.2008-0990)

Winship AL, Koga K, Menkhorst E, Van Sinderen M, Rainczuk K, Nagai M, Cuman C, Yap J, Zhang JG, Simmons D, et al. 2015 Interleukin-11 alters placentation and causes preeclampsia features
๑) 2018 Society for Endocrinology Published by Bioscientifica Ltd. Printed in Great Britain 
in mice. PNAS 112 15928-15933. (https://doi.org/10.1073/ pnas.1515076112)

Yao TP, Oh SP, Fuchs M, Zhou ND, Ch'Ng LE, Newsome D, Bronson RT, Li E, Livingston DM \& Eckner R 1998 Gene dosage-dependent embryonic development and proliferation defects in mice lacking the transcriptional integrator p300. Cell 93 361-372. (https://doi. org/10.1016/S0092-8674(00)81165-4)
Zhang C, Large MJ, Duggavathi R, DeMayo FJ, Lydon JP, Schoonjans K, Kovanci E \& Murphy BD 2013 Liver receptor homolog-1 is essential for pregnancy. Nature Medicine 19 1061-1066. (https://doi. org/10.1038/nm.3192)

Zhang D, Chang X, Bai J, Chen ZJ, Li WP \& Zhang C 2016 The study of cyclooxygenase 2 in human decidua of preeclampsia. Biology of Reproduction 95 56. (https://doi.org/10.1095/biolreprod.115.138263)

Received in final form 13 December 2017

Accepted 20 December 2017

Accepted Preprint published online 22 December 2017 